\title{
The Use of Giant Vesicles for Medical Applications: A Trend in the Last Decade
}

\author{
Taro Toyota, ${ }^{1 *}$ Yiting Zhang, ${ }^{2,3}$ and Hideki Hayashi ${ }^{2,3}$ \\ ${ }^{1}$ Department of Basic Science, Graduate School of Arts and Sciences, The University of Tokyo, \\ 3-8-1 Komaba, Meguro, Tokyo 153-8902, Japan \\ ${ }^{2}$ Center for Frontier Medical Engineering, Chiba University, \\ 1-33 Yayoi-cho, Inage-ku, Chiba 263-8522, Japan \\ ${ }^{3}$ Department of Frontier Surgery, Graduate School of Medicine, Chiba University, \\ 1-8-1 Inohana, Chuo-ku, Chiba-shi, Chiba 260-8670, Japan
}

(Received September 28, 2020; accepted December 7, 2020)

Keywords: giant vesicles, phospholipid, amphiphile, emulsion, cell marker, tissue marker, controlled release

A giant vesicle (GV) is composed of an amphiphile and a closed bilayer membrane with a diameter of $1 \mu \mathrm{m}$ or more in water. GVs composed of phospholipids are attracting attention as cell models because their constituent molecules, structure, and size resemble those of cell membranes. In the last decade, with the development of GV preparation methods, functionalized GVs that sense a stimulus as an input and can give a corresponding output have been reported as new medical molecular devices. This technical report overviews the applicability of GVs.

\section{Introduction}

When an amphiphile, with both a hydrophilic part and a hydrophobic part at the ends, is dispersed in water, molecular self-assemblies such as micelles and vesicles autonomously appear [Fig. 1(a)] A vesicle is a closed bilayer membrane of amphiphiles with hydrophobic parts facing each other. Nanometer-size vesicles are characterized as either small vesicles (less than ca. 100 $\mathrm{nm}$ ) or large vesicles (ca. $100 \mathrm{~nm}$ to $1 \mu \mathrm{m}$ ). Vesicles with a diameter of $1 \mu \mathrm{m}$ or more are called giant vesicles $(\mathrm{GVs}){ }^{(1)} \mathrm{GVs}$ are the same size as cells and can be individually observed in real time under an optical microscope [Fig. 1(b)]. As a chemical model that mimics cells, GVs have recently attracted interest in supramolecular chemistry and a wide range of research fields such as physics, chemistry, life sciences, and bioengineering.

Small vesicles and large vesicles are relatively effortlessly homogenized in size, shape, and internal structure; hence, they are widely used in pure and applied sciences, such as in drug delivery systems. ${ }^{(2)}$ For over 50 years, research on GVs has not been prevalent as they are considered difficult to handle quantitatively with good reproducibility. GVs prepared using conventional methods have significant variations in size, shape, and internal structure. In recent years, GV preparation methods have been greatly improved, and active research is

*Corresponding author: e-mail: cttoyota@mail.ecc.u-tokyo.ac.jp

https://doi.org/10.18494/SAM.2021.3072 

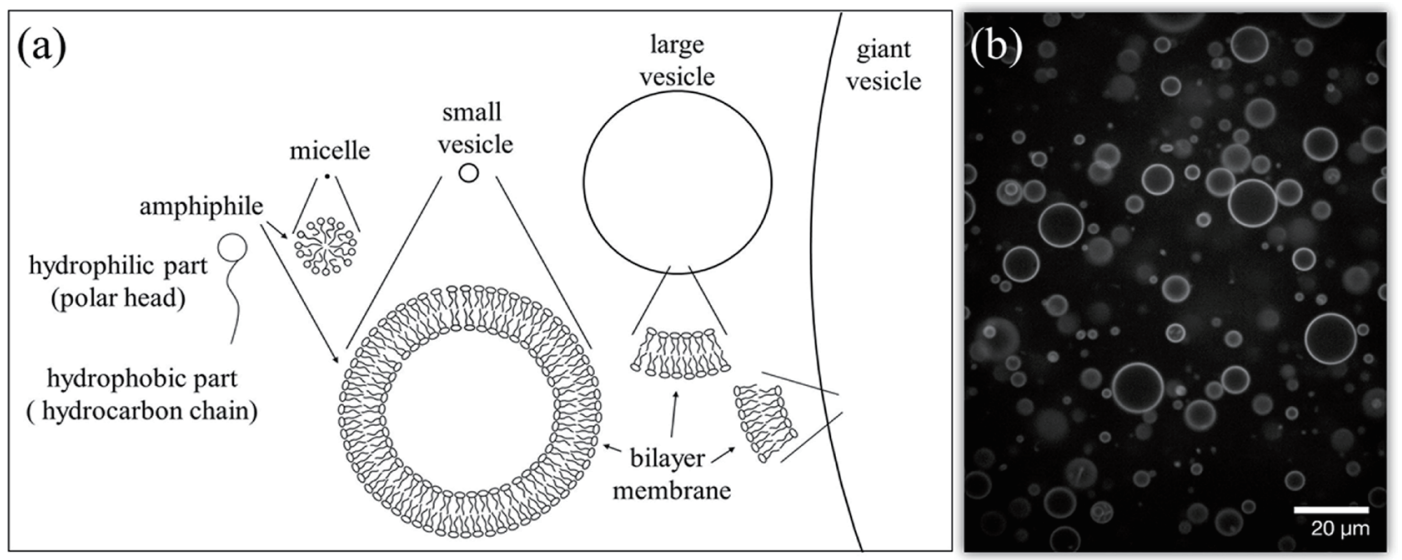

Fig. 1. (a) Schematic illustration of micelles and vesicles. (b) Confocal laser scanning fluorescence microscopy image of GVs stained by a synthesized fluorescent phospholipid.

being conducted on the application of GVs. Here, we introduce the recent improvements in GV preparation and provide an overview of the medical applications of GV at preclinical stages.

\section{Preparation of GVs}

GVs include giant unilamellar vesicles (GUVs) consisting of a single bilayer membrane and giant multilamellar vesicles (GMVs) that are closed by overlapping several bilayer membranes. GMVs have fewer inner water regions than GUVs of the same diameter, making it difficult to encapsulate water-soluble substances and water-dispersed particles with a high volume ratio. The multiple nested membrane structure of GMVs causes a fault in the control of the membrane dynamics of sensing and releasing. Therefore, the preparation methods for GUVs have primarily been developed in the last decade. GUV preparation is usually associated with one of four methods: the thin film swelling method, water-in-oil (W/O) emulsion template method, jetting method, and water-in-oil-in-water (W/O/W) double emulsion templating method (Fig. 2). ${ }^{(3)}$

In 1969, the first preparation method of GVs using a dry thin film of a phospholipid (a type of amphiphile, which is a primary component of the cell membrane) was reported and this preparation was named the thin film swelling method. ${ }^{(4,5)}$ In this method, GUVs are formed by the swelling of bilayer membranes on a thin film after water (or a buffered solution) is added. A patterning technology that involves applying a dry thin film to a glass substrate with a microfabricated stamp affords size-controlled GUVs. ${ }^{(6,7)}$

The W/O emulsion template method involves wrapping W/O emulsion droplets (surrounded by an amphiphile monolayer) with an amphiphile monolayer formed at the interface between the emulsion and water phases. ${ }^{(8)}$ The use of centrifugation for the wrapping is common. Several research groups have established new laboratory-built devices and novel methods, including the continuous droplet interface crossing encapsulation (cDICE) method ${ }^{(9)}$ and droplet-shooting and size-filtration (DSSF) method, ${ }^{(10)}$ for controlling the size of emulsion droplets. 
(a)

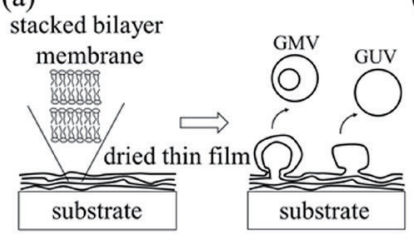

(b)

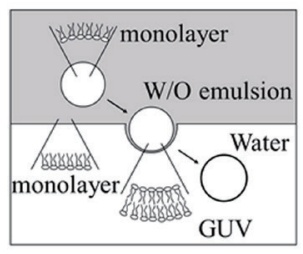

(c)

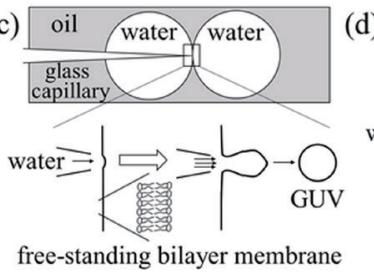

(d)

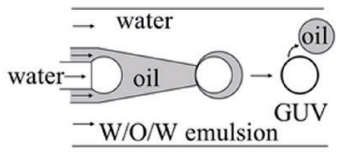

Fig. 2. Schematic illustrations of the thin film swelling method (a), W/O emulsion template method (b), jetting method (c), and W/O/W double emulsion templating method (d).

Along with the recent development of microfabrication techniques, the $\mathrm{W} / \mathrm{O}$ emulsion template method was improved, ${ }^{(11)}$ and new methods, including the jetting method and the W/ $\mathrm{O} / \mathrm{W}$ double emulsion templating method, were established. The jetting method is based on a free-standing bilayer membrane (called a black lipid membrane) and a glass capillary. GUVs are formed by a process resembling that of blowing soap bubbles. ${ }^{(12)}$ The $\mathrm{W} / \mathrm{O} / \mathrm{W}$ double emulsion templating method involves producing uniform $\mathrm{W} / \mathrm{O} / \mathrm{W}$ double emulsion droplets in a microfabricated fluidic device and obtaining GUVs by utilizing the phase separation of oil from the droplets. ${ }^{(13,14)}$ Although there are still some limitations to the versatility of these methods (Table 1), such as the use of reagents and obtaining appropriate sizes, GV preparation methods using microfabricated fluidic devices are expected to develop technologically and promote the application of GVs.

Table 1

Advantages and disadvantages of four preparation methods of GVs. ${ }^{(3)}$

\begin{tabular}{|c|c|c|c|c|}
\hline & $\begin{array}{l}\text { Thin film swelling } \\
\text { method }\end{array}$ & $\begin{array}{l}\text { W/O emulsion template } \\
\text { method }\end{array}$ & Jetting method & $\begin{array}{l}\mathrm{W} / \mathrm{O} / \mathrm{W} \text { double emulsion } \\
\text { templating method }\end{array}$ \\
\hline Description & $\begin{array}{l}\text { GVs formed by } \\
\text { swelling of stacked } \\
\text { bilayer membranes } \\
\text { (thin film) after } \\
\text { adding water (or } \\
\text { buffered solution). }\end{array}$ & $\begin{array}{l}\text { W/O emulsion droplets } \\
\text { surrounded by } \\
\text { amphiphile monolayer } \\
\text { wrapped by another } \\
\text { amphiphile monolayer } \\
\text { formed at interface } \\
\text { between emulsion and } \\
\text { water phases. }\end{array}$ & $\begin{array}{l}\text { Free-standing } \\
\text { bilayer membrane } \\
\text { extended and } \\
\text { swollen to form } \\
\text { GUVs by flow } \\
\text { through glass } \\
\text { capillary. }\end{array}$ & $\begin{array}{l}\text { Uniform } \mathrm{W} / \mathrm{O} / \mathrm{W} \\
\text { double emulsion } \\
\text { droplets produced in } \\
\text { microfabricated fluidic } \\
\text { device and transformed } \\
\text { into GUVs via phase } \\
\text { separation of oil from } \\
\text { droplets. }\end{array}$ \\
\hline Advantages & $\begin{array}{l}\text { Simple procedure. } \\
\text { Many types of } \\
\text { amphiphiles in use. } \\
\text { No oil remaining in } \\
\text { membrane. }\end{array}$ & $\begin{array}{l}\text { Simple procedure. } \\
\text { GUVs mainly produced. } \\
\text { High encapsulation } \\
\text { efficiency. }\end{array}$ & $\begin{array}{l}\text { GUVs mainly } \\
\text { produced. } \\
\text { High encapsulation } \\
\text { efficiency. } \\
\text { Many types of } \\
\text { amphiphiles in use. } \\
\text { Uniform size. }\end{array}$ & $\begin{array}{l}\text { GUVs mainly produced. } \\
\text { High encapsulation } \\
\text { efficiency. } \\
\text { Many types of } \\
\text { amphiphiles in use. } \\
\text { Uniform size. } \\
\text { High throughput. }\end{array}$ \\
\hline Disadvantages & $\begin{array}{l}\text { Mixture of GUVs } \\
\text { and GMVs. } \\
\text { Difficult to achieve } \\
\text { uniform size. } \\
\text { Low encapsulation } \\
\text { efficiency. }\end{array}$ & $\begin{array}{l}\text { Difficult to achieve } \\
\text { uniform size. } \\
\text { Some amphiphiles are } \\
\text { not applicable. } \\
\text { Oil remaining in } \\
\text { membrane. }\end{array}$ & $\begin{array}{l}\text { Specific device } \\
\text { needed. } \\
\text { Oil remaining in } \\
\text { membrane. }\end{array}$ & $\begin{array}{l}\text { Specific device needed. } \\
\text { Oil remaining in } \\
\text { membrane. }\end{array}$ \\
\hline
\end{tabular}




\section{GV-based Sensors}

GVs have drawn considerable attention as new sensing devices. They provide a micrometersize reaction field that is surrounded by a soft boundary, and are composed of biodegradable molecules (such as phospholipids), and possess membrane proteins anchored in the phospholipid bilayer membrane, which act as effective and specialized molecular sensors. Yanagisawa et al. reported that KcsA, a potassium ion channel, can change its function in the inward and outward directions when incorporated into GUVs produced using the W/O emulsion template method. ${ }^{(15)}$ Dwidar et al. reported a GUV sensor for histamine, a membrane-permeant molecule, by constructing a cell-free protein synthesis system that contains RNA, which responds to histamine. ${ }^{(16)}$ Hamada et al. synthesized an insect pheromone receptor, which was a complex of two membrane proteins, BmOR1 and BmOrco, in GUVs and demonstrated that this receptor functions in GUVs using the patch clamp technique [Fig. 3(a)]. ${ }^{(17)}$ As shown in Fig. 3(b), at a folding potential of $-70 \mathrm{mV}$, inward currents of several picoamperes were recorded while the pheromone was added to the GUVs. Since the current was within the range of the amplitude for the single-channel conductance of insect pheromone receptors found in living cells, ${ }^{(18)}$ it was indicated that BmOR1 and BmOrco fold properly and form heteromeric complexes on the vesicular membrane. Further research on GV-based sensors with high substrate specificity and reaction specificity is expected to continue to rapidly increase.

(a)

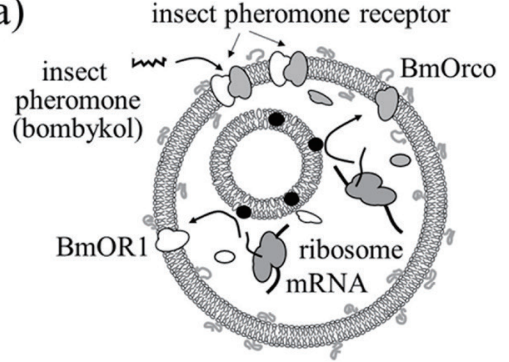

(b)

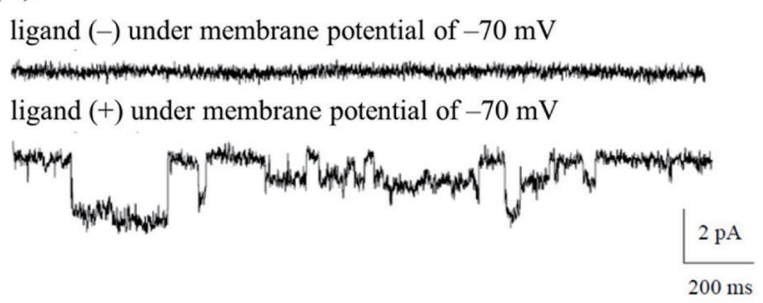

Fig. 3. (a) Schematic illustration of a GUV synthesizing an insect pheromone receptor. (b) Ion current traces of the GUV before ligand (bombykol) stimulation and during ligand stimulation recorded with a voltage clamp at $-70 \mathrm{mV}$.

\section{GV-based Cell/Tissue Markers}

In recent years, with a declining birthrate and an aging population in many countries, minimally invasive treatments such as endoscopic surgery are in high demand for improving patients' quality of life. Palpation of objects is no longer available with these techniques, and surgeons need to locate target lesions inside organs only with the aid of video images of the objects. This situation complicates surgical procedures. For example, laparoscopic surgeries in patients with early gastric cancer occasionally require additional assistance from a gastroendoscope to localize the lesion during surgery. ${ }^{(19,20)}$ Toyota and coworkers have proposed 
the concept of a cell/tissue marker based on GV constructs, in which a large amount of multiple contrast agents can be encapsulated using the W/O emulsion template method (Fig. 4). ${ }^{(21,22)}$ First, GV aggregates containing a near-infrared fluorescent (NIRF) dye are preoperatively administered in a spot manner for identifying the margin of the lesion of interest using a gastroendoscope from inside of the stomach. Second, the location and extent of the lesion are shown as a dotted line on the NIRF laparoscopic images observed from outside of the stomach during surgery. In fact, injection points of GV aggregates have been shown to be clearly detected without severe blurring up to $18 \mathrm{~h}$ after administration on animal models. Hayashi et al. demonstrated that preoperative administration of the same GV aggregates with an X-ray contrast medium as well as an NIRF dye also enables the identification of lesions undetectable with X-ray CT examination. ${ }^{(23)}$ Early-stage malignant diseases as targets for such minimally invasive surgeries cannot be visualized by conventional laparoscopy or X-ray CT. However, this novel tissue marker encapsulating both an NIRF dye and X-ray media in a single material could contribute to precise preoperative planning and intraoperative navigation for various surgeries. The same group also started to develop a novel active tissue marker based on GV aggregates that are activatable with ultrasound irradiation and release a liposomal tracer for detecting sentinel lymph nodes or the first draining site from a main tumor. ${ }^{(24)}$

(a)

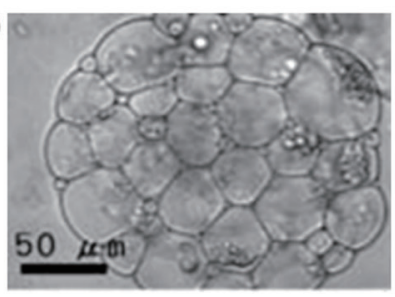

(b)

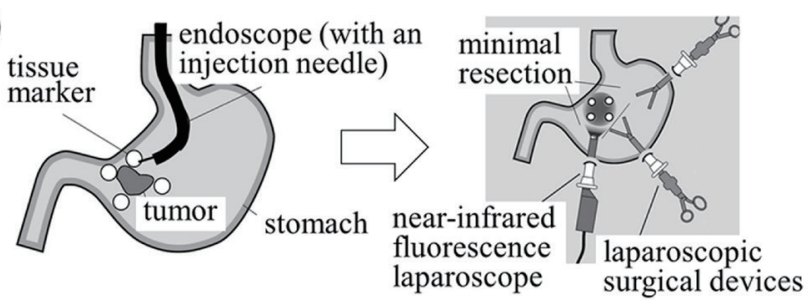

Fig. 4. (a) Phase contrast microscopy image of a GV aggregate containing vesicles with a NIRF dye. (b) Schematic illustration of the conceptual process of laparoscopic gastrectomy using a novel tissue marker of a GV aggregate.

\section{GV-based Controlled Releasers}

Further research on GVs with regard to medical applicability was conducted by Chen et al., which included the construction of artificial pancreatic $\beta$ cells that released insulin in response to glucose. ${ }^{(25)}$ The GV used in their study encapsulated polymer-coated large vesicles containing insulin (Fig. 5). Since the inner leaflet of the GV and the outer leaflet of the large vesicles were modified with membrane-fusion peptides, the polymer coating the large vesicles prevented the membrane fusion unless the polymer was decomposed upon exposure to a low $\mathrm{pH}$. In response to glucose stimulation, insulin was released from the inside of the GV during the sequential process of $\mathrm{pH}$ decrease by glucose oxidase and catalase and the subsequent membrane fusion of the large vesicles driven by decomposition of the coating polymer. The $\mathrm{pH}$ in the GV could be repeatedly recovered by gramicidin A embedded in the GV membrane. When this GV was 


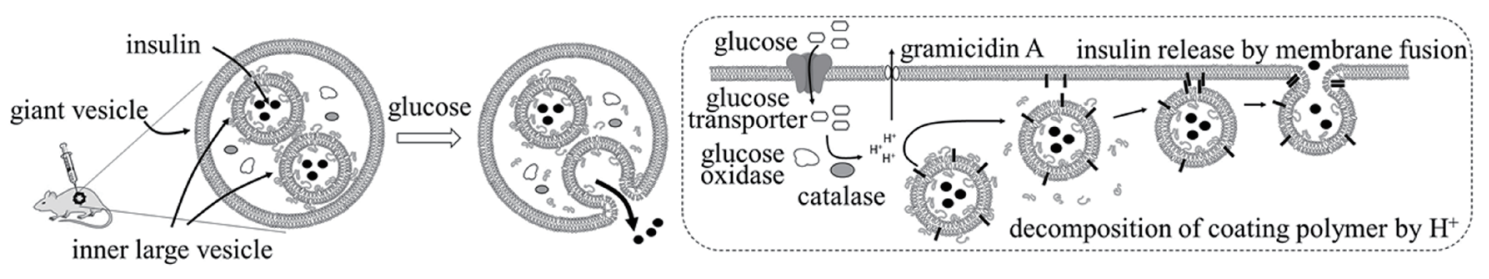

Fig. 5. Schematic illustration of insulin release from the GUV-large vesicle system in response to glucose. ${ }^{(25)}$

transplanted to mice with high blood glucose levels, the blood glucose levels decreased and returned to normal levels. Recently, Luo et al. demonstrated another medical applicability of GVs comprising a plasma membrane and modified by functional DNA for targeting tumor cells. ${ }^{(26)}$ The GVs contained anticancer drugs and near-infrared phototherapy reagents. After administrating the GVs into a tumor in mice and irradiating the tumor with near-infrared light, the weight of the tumor efficiently decreased. Such multimodality of GVs will attract more interest with regard to their medical applications.

\section{Summary}

Functionalized GVs have an increasing number of applications similar to those of cells and organelles as the GV technology continues to develop. GV-based sensors and controlled releasers constructed from known molecules may be inexpensive, easier to control, and have greater utility in future medical applications.

\section{Acknowledgments}

We thank Prof. Yutaka Tamura (Chiba University) and Prof. Masanori Fujinami (Chiba University) for their participation in productive discussions. This work was partly supported by KAKENHI (23750078 and 21750073 for TT, 17K10535 and 24591933 for HH, JP18J21091 for YZ), and Urakami Foundation for Food and Food Culture Promotion (for TT).

\section{References}

1 R. Dimova and C. M. Marques: The Giant Vesicle Book (CRC Press, Boca Raton, 2019). https://doi. org/10.1201/9781315152516

2 G. G. M. D’Souza: Liposomes Methods and Protocols (Springer, Berlin, 2017). https://doi.org/10.1007/978-14939-6591-5

3 T. Toyota and M. Morita: Bunseki 7 (2020) 255 (in Japanese).

4 J. P. Reeves and R. M. Dowben: J. Cell. Physiol. 73 (1969) 49. https://doi.org/10.1002/jcp.10407300108

5 M. I. Miglena and D. S. Dimitov: Faraday Discuss. Chem. Soc. 81 (1986) 303. https://doi.org/10.1039/ DC9868100303

6 P. Taylor, C. Xu, P. D. I. Fletcher, and V. N. Paunov: Chem. Commun. (2003) 1732. https://doi.org/10.1039/ B304059C

7 J. R. Howse, R. A. L. Jones, G. Battaglia, R. E. Ducker, G. J. Leggett, and A. J. Ryan: Nat. Mater. 8 (2009) 507. https://doi.org/10.1038/nmat2446

8 S. Pautot, B. J. Frisken, and D. A. Weitz: Langmuir 19 (2003) 2870. https://doi.org/10.1021/1a026100v 
9 M. Abkarian, E. Loiseau, and G. Massiera: Soft Matter 7 (2011) 4610. https://doi.org/10.1039/C1SM05239J

10 M. Morita, H. Onoe, M. Yanagisawa, H. Ito, M. Ichikawa, K. Fujiwara, H. Saito, and M. Takinoue: ChemBioChem 16 (2015) 2029. https://doi.org/10.1002/cbic.201500354

11 M. Matosevic and B. M. Paegel: J. Am. Chem. Soc. 133 (2011) 2798. https://doi.org/10.1021/ja109137s

12 K. Kamiya, R. Kawano, T. Osaki, K. Akiyoshi, and S. Takeuchi: Nat. Chem. 8 (2016) 881. https://doi. org/10.1038/nchem. 2537

13 H. C. Shum, D. Lee, I. Yoon, T. Kodger, and D. A. Weitz: Langmuir 24 (2008) 7651. https://doi.org/10.1021/ la801833a

14 S. Deshpande, Y. Caspi, A. E. C. Meijering, and C. Dekker: Nat. Commun. 7 (2016) 10447. https://doi. org/10.1038/ncomms10447

15 M. Yanagisawa, M. Iwamoto, A. Kato, K. Yoshikawa, and S. Oiki: J. Am. Chem. Soc. 133 (2011) 11774. https://doi.org/10.1021/ja2040859

16 M. Dwidar, Y. Seike, S. Kobori, C. Whitaker, T. Matsuura, and Y. Yokobayashi: J. Am. Chem. Soc. 141 (2019) 11103. https://doi.org/10.1021/jacs.9b03300

17 S. Hamada, M. Tabuchi, T. Toyota, T. Sakurai, T. Hosoi, T. Nomoto, K. Nakatani, M. Fujinami, and R. Kanzaki: Chem. Commun. 50 (2014) 2958. https://doi.org/10.1039/C3CC48216B

18 K. Sato, M. Pellegrino, T. Nakagawa, T. Nakagawa, L. B. Vosshall, and K. Touhara: Nature 452 (2008) 1002. https://doi.org/10.1038/nature06850

19 H. Gunji, D. Horibe, M. Uesato, M. Kano, K. Hayano, N. Hanari, H. Kawahira, H. Hayashi, and H. Matsubara: Dig. Surg. 34 (2017) 12. https://doi.org/10.1159/000447606

20 T. Mitsui, K. Niimi, H. Yamashita, O. Goto, S. Aikou, F. Hatao, I. Wada, N. Shimizu, M. Fujishiro, K. Koike, and Y. Seto: Gastric Cancer 17 (2014) 594. https://doi.org/10.1007/s10120-013-0291-5

21 T. Toyota, N. Ohguri, K. Maruyama, M. Fujinami, T. Saga, and I. Aoki: Anal. Chem. 84 (2012) 3952. https:// doi.org/10.1021/ac2031354

22 H. Hatayama, T. Toyota, H. Hayashi, T. Nomoto, and M. Fujinami: Anal. Sci. 30 (2014) 225. https://doi. org/10.2116/analsci.30.225

23 H. Hayashi, T. Toyota, S. Goto, A. Ooishi, T. Gao, L. B. Ee, H. Hatayama, T. Nomoto, M. Fujinami, and H. Matsubara: Surg. Endosc. 29 (2015) 1445. https://doi.org/10.1007/s00464-014-3822-1

24 R. Yahagi, K. Yoshida, Y. Zhang, M. Ebata, T. Toyota, T. Yamaguchi, and H. Hayashi: Jpn. J. Appl. Phys. 55 (2016) 07KF21. https://doi.org/10.7567/JJAP.55.07KF21

25 Z. Chen, J. Wang, W. Sun, E. Archibong, A. R. Kahkoska, X. Zhang, Y. Lu, F. S. Ligler, J. B. Buse, and Z. Gu: Nat. Chem. Biol. 14 (2018) 86. https://doi.org/10.1038/nchembio.2511

26 C. Luo, X. Hu, R. Peng, H. Huang, Q. Liu, and W. Tan: ACS Appl. Mater. Interfaces 11 (2019) 43811. https:// doi.org/10.1021/acsami.9b11223.

\section{About the Authors}

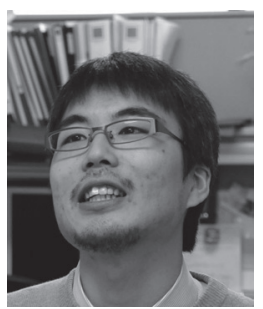

Taro Toyota received his B.S. degree from The University of Tokyo, Japan, in 2000. He received his Ph.D. degree from The University of Tokyo in 2005 and is now an associate professor here. He was an assistant professor at Chiba University from 2006 to 2009 and a researcher of PRESTO, JST from 2009 to 2015. His research focuses on molecular assembly in non-equilibrium states and open-system chemistry. (cttoyota@mail.ecc.u-tokyo.ac.jp)

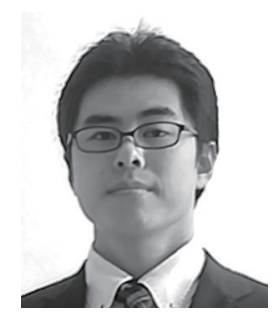

Yiting Zhang received his B.S. degree from Chiba University, Japan, in 2015, and his M.S. degree from Chiba University, Japan, in 2017. Since 2017, he has been a doctoral student at Chiba University and a member of JSPS with a DC1 Research Fellowship for Young Scientists. His research focuses on nano/ microcarrier drug delivery and cancer therapy. (aada2433@chiba-u.jp) 


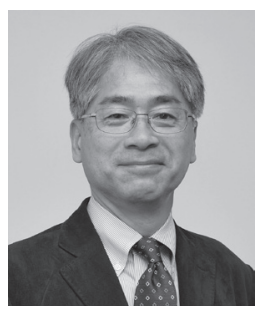

Hideki Hayashi received his B.S. and Ph.D. degrees from Chiba University, Japan, in 1985 and 1992, respectively. From 1996 to 2003, he was an assistant professor at Chiba University Hospital, Japan. From 2003 to 2005, he was an associate professor at the Center for Frontier Medical Engineering, Chiba University (CFME). He has been a professor at CFME since 2005. His research interests are in minimally invasive surgery and associated technologies. (hhayashi@faculty.chiba-u.jp) 